\title{
Perancangan Aplikasi Pemetaan Demam Berdarah di Kota Bandung Menggunakan Unified Software Development Process
}

\author{
Dani Hamdani ${ }^{1}$, RAE Virgana ${ }^{2}$ \\ Prodi Sistem Informasi, Universitas Widyatama \\ (dani.hamdani@widyatama.ac.id, rae.virgana@widyatama.ac.id)
}

\begin{abstract}
ABSTRAK
Surveilans demam berdarah merupakan suatu proses tindak lanjut atas adanya laporan KDRS demam berdarah di suatu daerah. Sistem Informasi Geografis merupakan sebuah sistem yang mampu menampilkan data spasial dengan baik. Tulisan ini membahas bagaimana SIG dijadikan salah satu solusi yang bisa diterapkan dalam menyajikan informasi peta surveilans demam berdarah di kota Bandung. Sehingga, pihak berwenang bisa melihat peta sebaran penderita demam berdarah di Bandung dan hasil surveilans yang telah dilakukan oleh pihak puskesmas terkait untuk selanjutnya bisa dijadikan bahan pertimbangan bagi dinas terkait dalam mengambil tindakan penanggulangan terhadap penyakit demam berdarah. Dalam menganalisis kebutuhan sistem dan memodelkannya, penulis menggunakan UML (Unified Modeling Language). Target luaran dari penelitian ini berupa desain sistem informasi geografis pemetaan surveilans demam berdarah di kota Bandung.
\end{abstract}

Kata Kunci : surveilans;gis;dengue.

\section{PENDAHULUAN}

Teknologi Sistem Informasi Geografis (SIG) adalah sistem yang sangat baik dalam menampilkan gambaran data spasial dan atribut-atributnya. SIG bisa digunakan sebagai alat bantu yang sangat interaktif dalam meningkatkan pemahaman pengguna tentang konsep-konsep kependudukan, lokasi, spasial, dan lain-lain.

Sistem informasi geografis dapat diaplikasikan diberbagai bidang ilmu, pekerjaan dan peristiwa. Sebagai contoh bidang kesehatan, dimana SIG dapat menyediakan data tentang pola spasial penyebaran penderita suatu penyakit, distribusi unit-unit medis berikut fasilitas pendukungnya.

Surveilans merupakan suatu usaha dalam mengendalikan penyakit menular seperti penyakit demam berdarah. Dan sebagaimana telah kita ketahui bersama bahwa penyakit ini (DB), sudah memakan banyak korban yang sudah tidak terhitung jumlahnya, penyakit ini juga tidak hanya menjangkit masyarakat dari tertentu saja. Saat ini dinas kesehatan kota Bandung sudah memiliki aplikasi pelaporan Kewaspadaan Dini Rumah Sakit (KDRS) Demam Berdarah Online yang dapat memudahkan pelaporan penderita demam berdarah di kota Bandung. Namun, sistem tidak memberikan informasi secara visual dalam menampilkan data lokasi dan sebaran penderita DB, sehingga pihak pemerintah melalui dinas kesehatan kota memiliki kesulitan dalam mengetahui wilayah mana yang terkena dampak DBD mulai dari sebaran terendah hingga tertinggi [2].

Tujuan dari penelitian ini adalah untuk merancang desain sistem informasi geografis yang bisa memberikan gambaran terkait informasi surveillans demam berdarah di kota Bandung, sehingga diharapkan para pengambil kebijakan bisa mengambil tindakan yang tepat untuk menangani demam berdarah di kota Bandung.

Agar proses analisis dan perancangan sistem lebih jelas, maka Unified Software Development Proccess (USDP) dipilih oleh peneliti sebagai salah satu mdetode pendekatan yang digunakan bersama dengan konsep MVC (Model View Controller) sebagai pendekatan perancangan arsitektur software. 


\section{KAJIAN PUSTAKA}

Pada bagian kajian pustaka, peneliti menguraikan landasan-landasan teori yang dipilih berdasarkan literatur yang digunakan sebagai acuan serta dasar keilmuan yang terkait dengan topik kajian penelitian yang dilakukan.

\subsection{Sistem Informasi Geografis (SIG)}

Rhind mengemukakan bahwa, "Sistem informasi geografis adalah sistem komputer yang dapat menyimpan dan menggunakan data yang menggambarkan tempat - tempat di permukaan bumi." [1].

\subsection{Unified Software Development Process (USDP)}

Unified Software Development Process adalah sebuah metodologi yang digunakan untuk pengembangan perangkat lunak, terutama perangkat lunak yang berorientasi objek. Metodologi ini pertama kali diperkenalkan oleh Rational Team, yang pada perkembangan selanjutnya metodologi ini disempurnakan kembali menjadi metodologi baru yang bernama Rational Unified Process (RUP), yang sekaligus menjadi cikal bakal tebentuknya kurang lebih tujuh metodologi lainnya.

Proses yang dicakup USDP tidaklah sesederhana jika dibandingkan metodologi klasik, seperti halnya waterfall ataupun iterative model. Hal ini disebabkan USDP lebih sering digunakan untuk membangun sebuah kerangka kerja (framework) yang bisa dikustomisasi untuk kepentingan organisasi dan proyek yang lebih spesifik. Dengan framework, bisa tercipta beragam aplikasi karena adanya konsep coding reuse, dimana coding yang sama bisa dipakai untuk keperluan aplikasi yang sejenis [3].

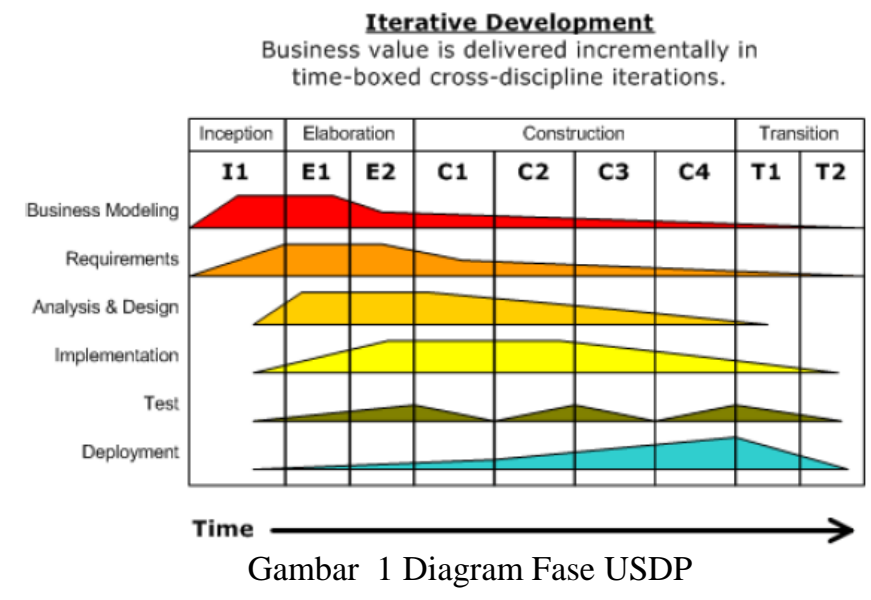

Berdasarkan gambar 1 dapat dilihat bahwa USDP terdiri atas 4 fase, yang terdiri dari Inception, Elaboration, Construction, serta Transition. Pada masing-masing fase terdapat 6 tahap kerja (iterasi) yang wajib dilakukan, yaitu Business Modeling, Requirements, Analysis \& Design, Implementation, Test, serta Deployment.

Berdasarkan gambar 1 juga kita bisa melihat grafik pada setiap fase memiliki penekanan pada beberapa tahap kerja. Contoh, pada fase Inception, maka tahap kerja yang lebih dipentingkan adalah Business Modeling. Sedangkan pada fase Elaboration, maka tahap kerja yang lebih dipentingkan adalah Business Modeling, Requirements, Analysis dan Design [3].

\section{METODE PENELITIAN}

Metodologi penelitian disusun dalam rangka untuk memudahkan proses analisis dan perancangan desain aplikasi dan dibagi ke dalam beberapa tahapan. Tahapan-tahapan tersebut dapat anda lihat pada Gambar 2. 


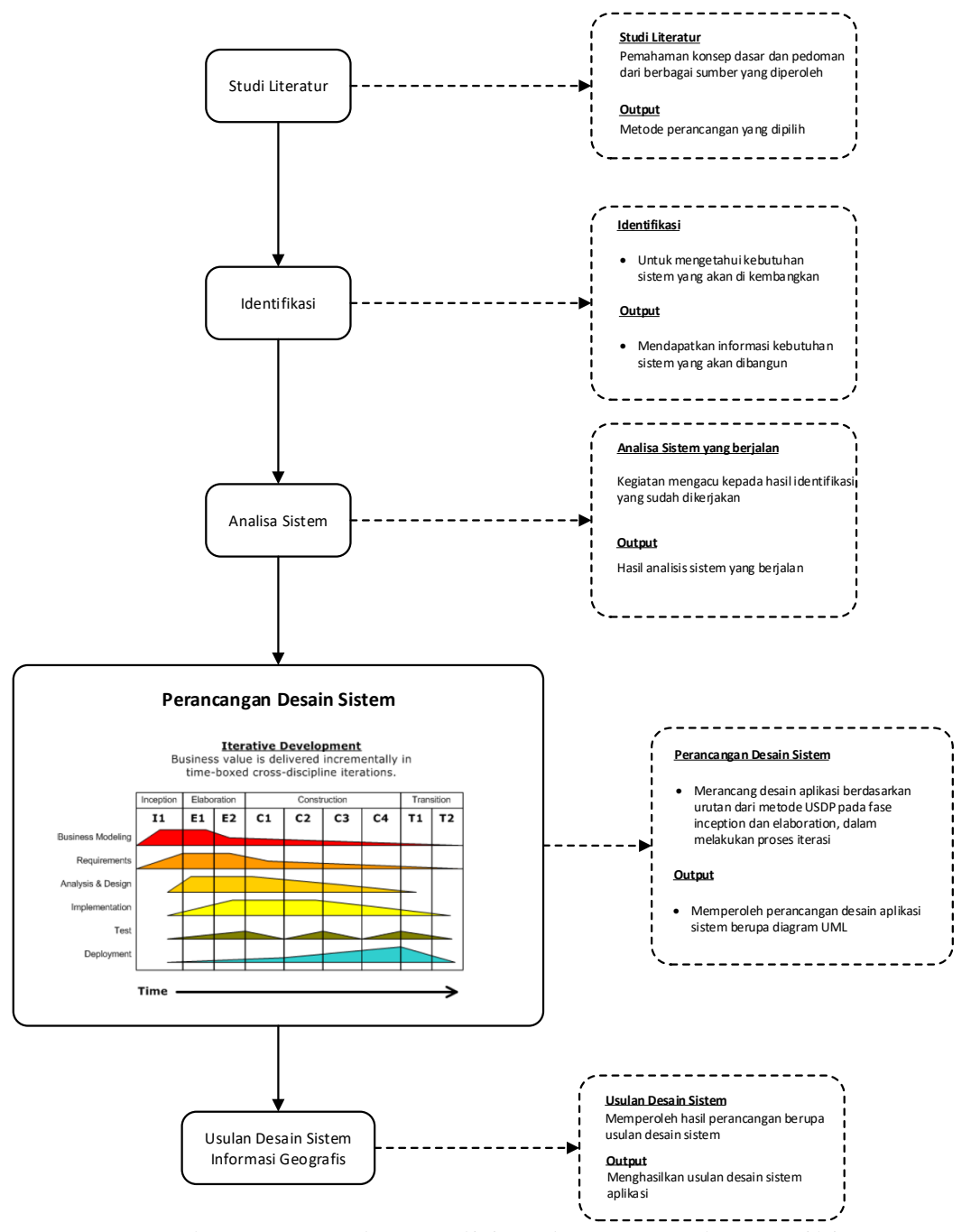

Gambar 2 Metode Penelitian dan Kerangka Pemikiran

1. Studi Literatur

Pada tahap ini, literatur-literatur dikumpulkan oleh peneliti, baik dari penelitian-penelitian sebelumnya maupun dari jurnal-jurnal ilmiah, baik dari dalam maupun luar negeri.

2. Identifikasi Masalah

Selanjutnya pada tahap identifikasi masalah, peneliti melakukan identifikasi permasalahan yang ada. Selanjutnya berdasarkan permasalahan tersebut dibuatlah hipotesis, kemudian dilakukan penelitian dan uji coba untuk membuktikan hipotesis tersebut.

3. Analisa Sistem

Kemudian pada tahap analisa dilakukan analisa terhadap sistem yang sedang berjalan. Agar kita bisa mengetahui dengan baik, apa saja kebutuhan dari model sistem yang harus dibangun.

4. Perancangan Desain Sistem

Pada tahap ini dilakukan pembuatan model sistem informasi geografis, pembuatan Use Case Scenario, Activity Diagram, dan Class Diagram, serta tidak lupa contoh/prototype tampilan interface dari sistem informasi geografisnya

5. Model

Model yang dibuat adalah model sistem informasi geografis yang dapat memberikan informasi kewilayahan dari sebaran demam berdarah di Kota Bandung. 


\section{HASIL DAN PEMBAHASAN}

Pada bagian ini akan diuraikan hasil dari penelitian yang telah dilakukan.

\subsection{Analisis Sistem}

Berikut ini adalah hasil dari analisis yang telah dilakukan pada Dinas Kesehatan Kota Bandung terkait sistem pelaporan KDRS Demam Berdarah yang sudah ada.

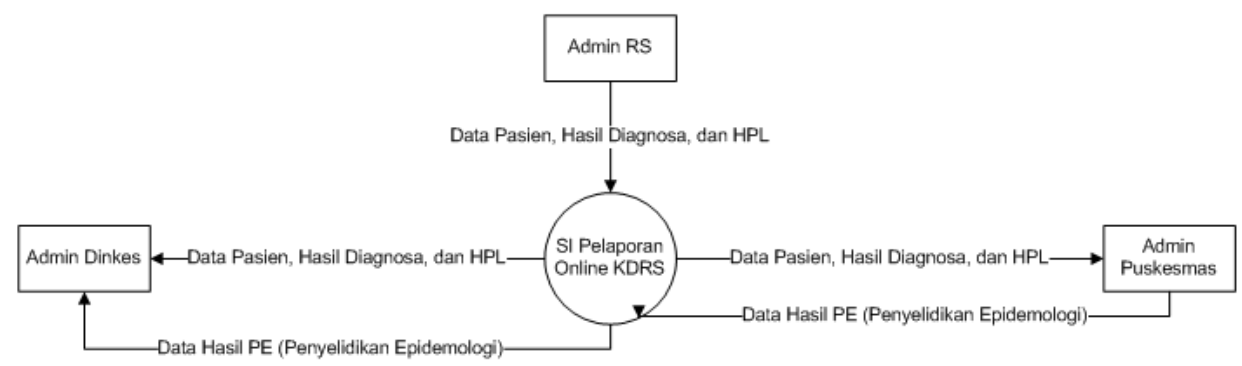

Gambar 3 Diagram Konteks SI Pelaporan Online KDRS

Detail dari diagram konteks pada gambar 3, bisa dilihat pada DFD di gambar 4.

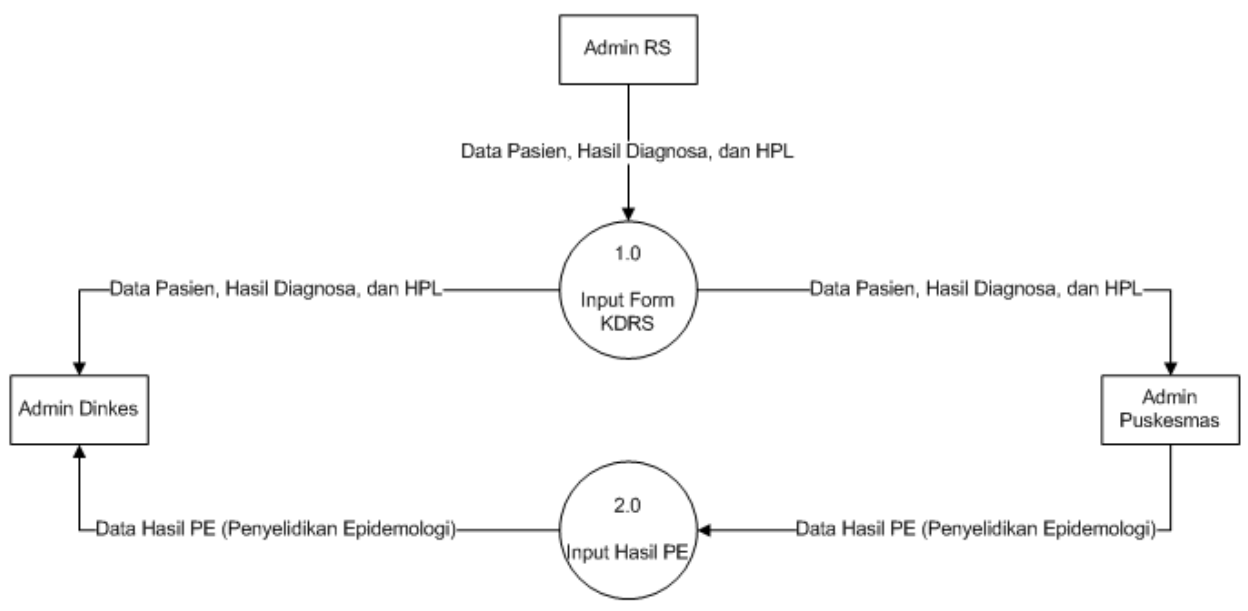

Gambar 4 DFD SI Pelaporan Online KDRS

\subsection{Perancangan Sistem}

Agar proses analisis dan perancangan lebih jelas, peneliti menggunakan pendekatan metode USDP (Unified Software Development Proccess). Metode ini adalah sebuah metodologi yang digunakan dalam kegiatan pengembangan software, khususnya yang berorientasi objek. Rational Team adalah yang pertama kali memperkenalkan metode ini ke publik, dimana dalam perkembangannya metode ini mengalami penyempurnaan untuk selanjutnya dikenal dengan nama Rational Unified Process (RUP). [3].

Dari analisis yang telah penulis lakukan sebelumnya, diketahui bahwa saat ini dinkes kota Bandung masih belum memiliki data sebaran demam berdarah dalam bentuk peta visual yang bisa lebih mudah dibaca dan dipahami oleh pihak yang berwenang. Data yang ada saat ini masih berupa tabel sehingga pihak dinas masih harus melakukan analisis lebih jauh lagi untuk menentukan daerah mana yang harus ditangani terlebih dahulu. 
Untuk memenuhi kebutuhan informasi pihak terkait, maka proses-proses yang terjadi digambarkan dalam bentuk usecase diagram yang dideskripsikan pada gambar 5 sampai gambar 7 . Dengan adanya use case diagram ini, developer diharapkan akan lebih mudah dalam merancang aplikasi karena mengetahui proses-proses apa saja yang perlu dirancang.

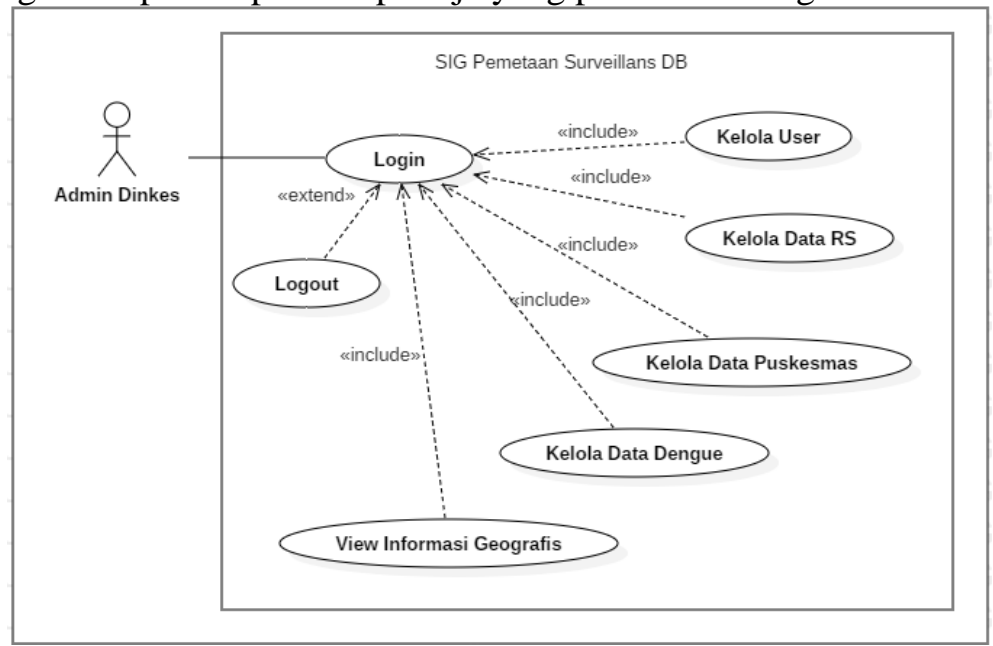

Gambar 5 Use Case Diagram SIG untuk Dinkes

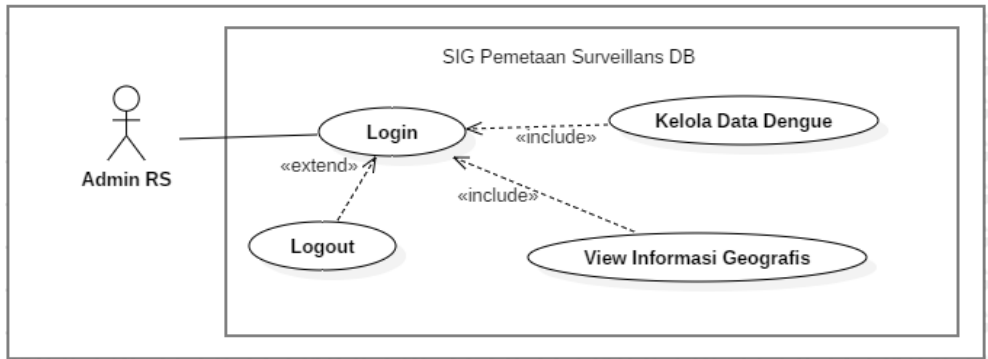

Gambar 6 Use Case Diagram SIG untuk RS

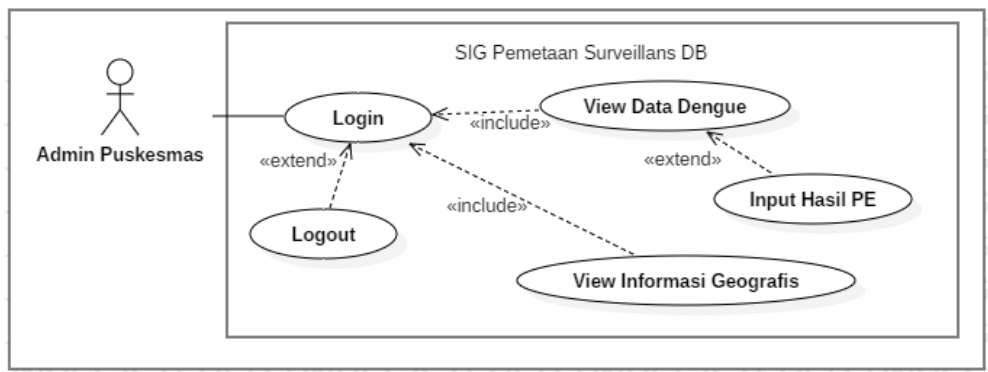

Gambar 7 Use Case Diagram SIG untuk Puskesmas

Selanjutnya penulis membuat class diagram untuk mengakomodir semua objek didalam setiap proses untuk menghasilkan sebuah informasi yang lebih baik. Whitten dan Bentley menjelaskan bahwa untuk menggambarkan pengelolaan objek beserta asosiasinya satu sama lain dalam suatu sistem bisa menggunakan class diagram[4]. Dan class diagram dari model sistem yang dibangun dapat dilihat pada gambar 8 . 


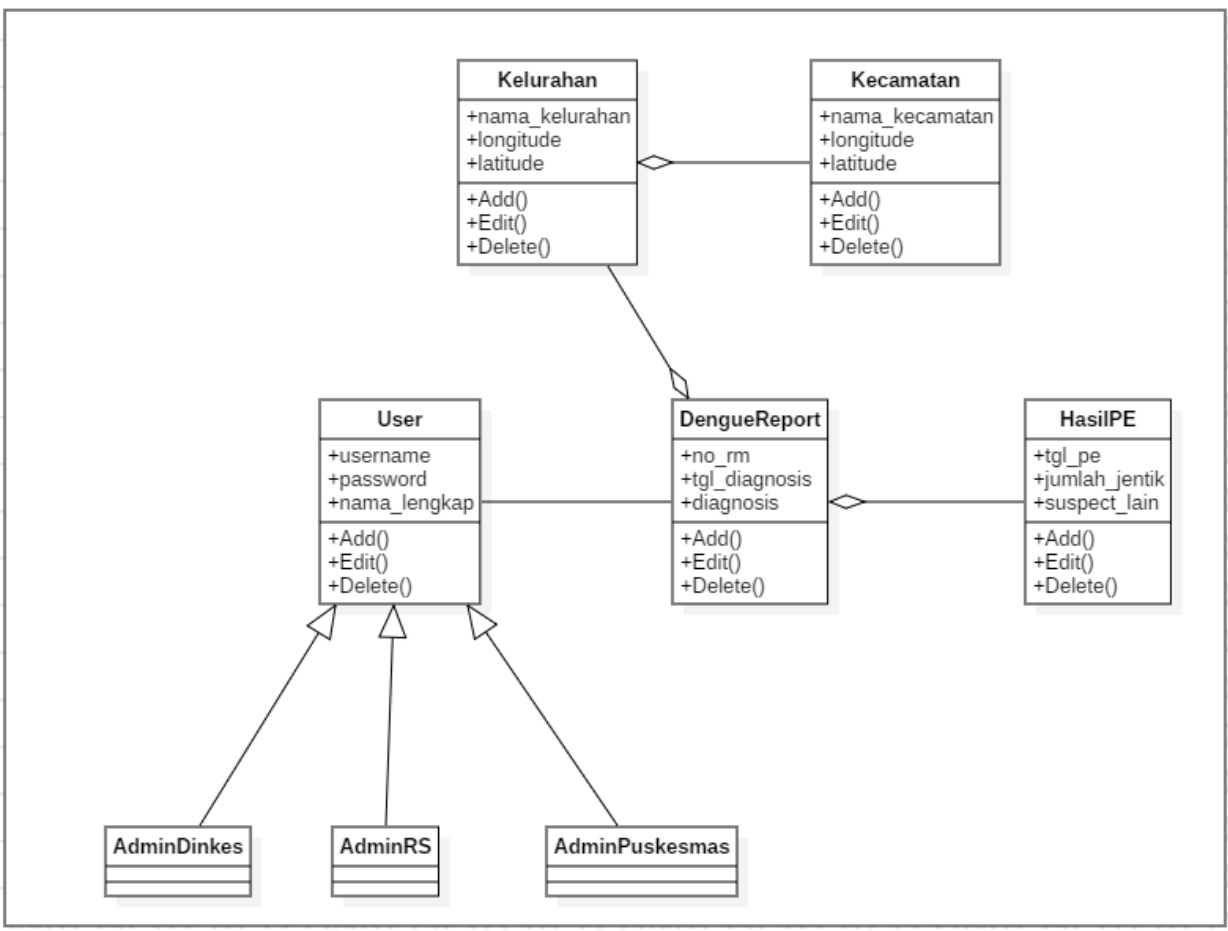

Gambar 8 Class Diagram SIG Sebaran DBD

\subsection{Tampilan Aplikasi}

Berikut ini adalah beberapa tampilan aplikasi yang sudah diimplementasikan.

\subsubsection{Halaman Login}

Halaman ini merupakan yang pertama kali dilihat oleh user setiap mengakses aplikasi.

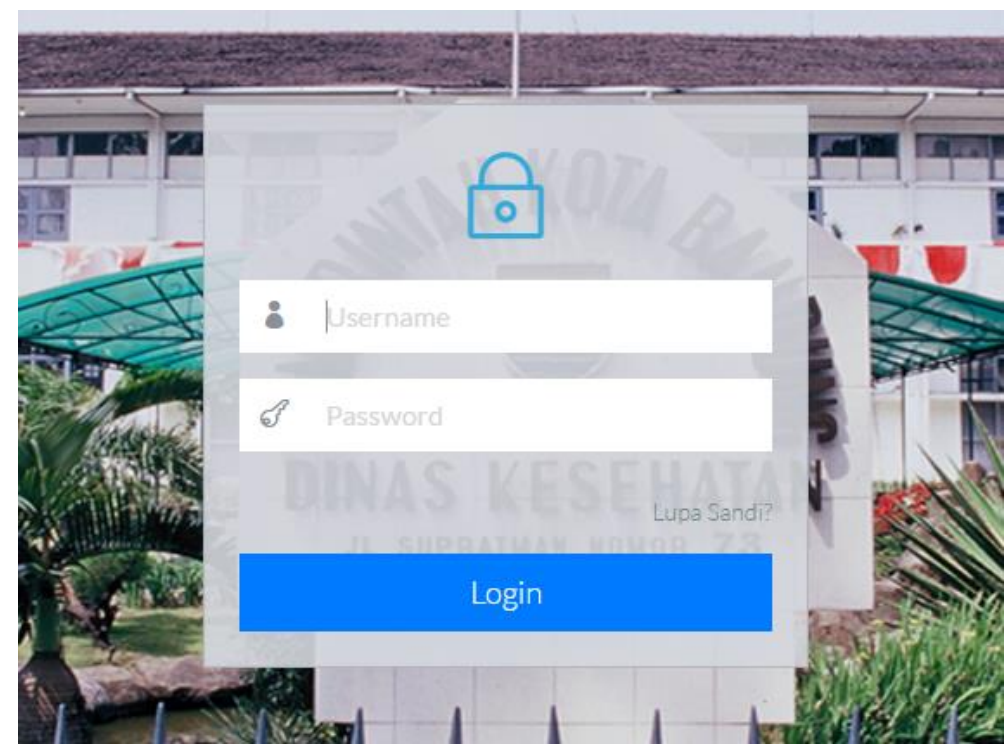

Gambar 9 Halaman Login

\subsubsection{Dashboard}

Halaman ini berisi informasi sebaran demam berdarah di Kota Bandung. 


\begin{tabular}{|c|c|}
\hline |JATI & 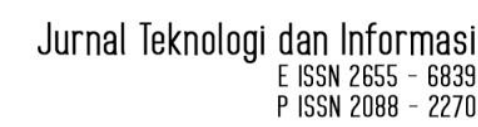 \\
\hline
\end{tabular}

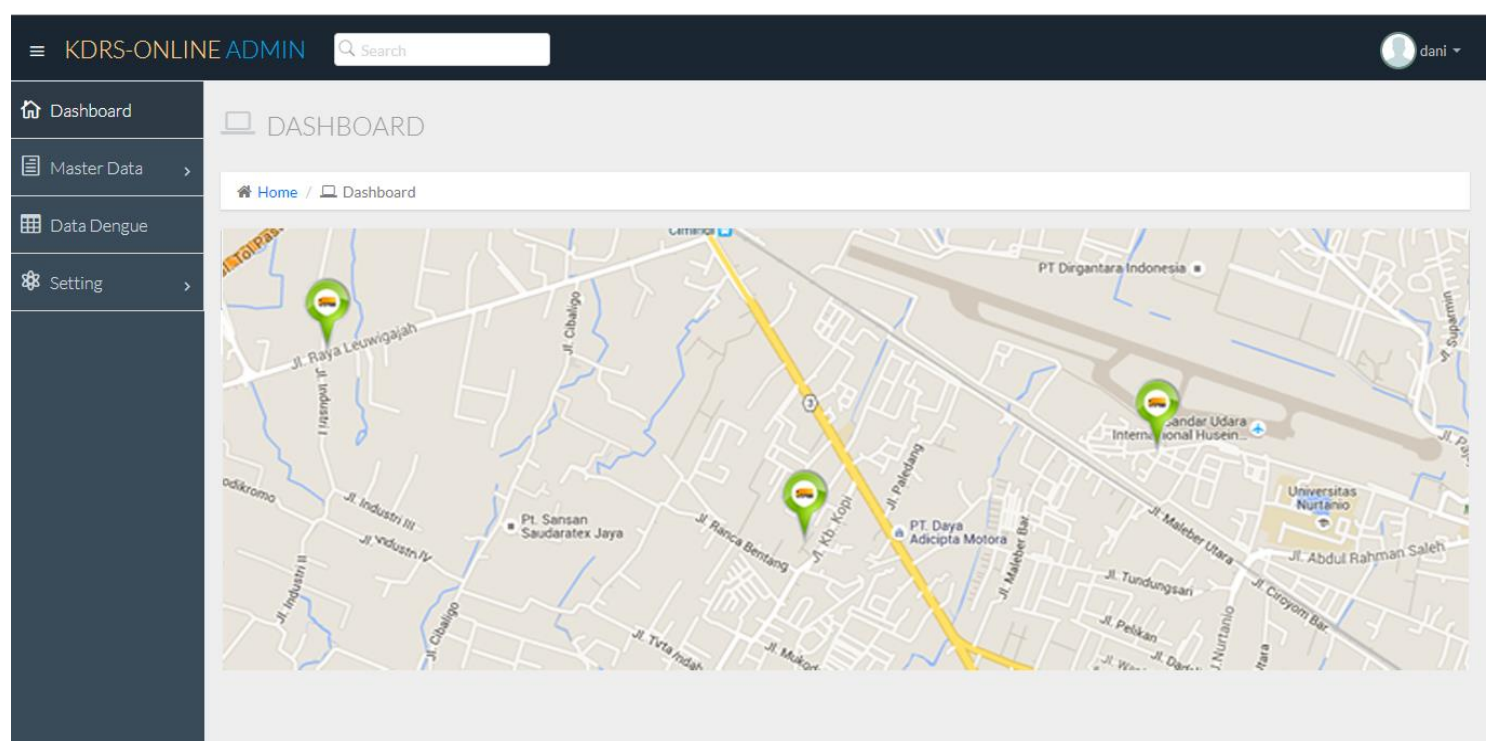

Gambar 10 Halaman Dashboard SIG

\subsubsection{Halaman Detail Sebaran}

Halaman ini berisi data detail sebaran yang menderita Demam Berdarah.

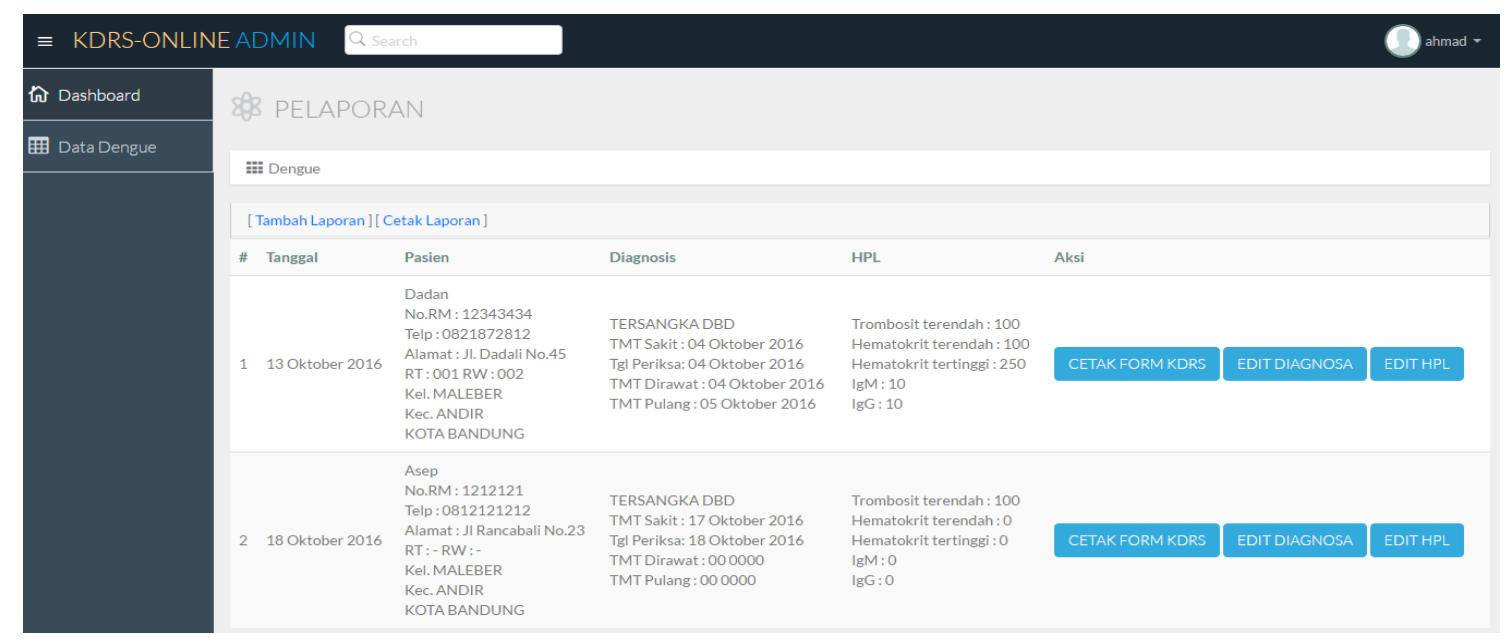

Gambar 11 Halaman Detail Sebaran DBD

\section{KESIMPULAN}

Dari hasil pembahasan yang telah diuraikan pada bagian sebelumnya, peneliti mengambil beberapa simpulan sebagai berikut:

1) Model sistem informasi geografis yang bisa menampilkan informasi sebaran pasien DBD dan tindak lanjutnya secara visual agar dapat menetapkan kebijakan yang lebih tepat dan cepat.

2) Model sistem informasi juga dapat memberikan informasi data hasil surveillans DBD.

3) Sosialisasi dalam kesadaran untuk proses pelaporan demam berdarah agar bisa lebih ditingkatkan lagi, agar bisa menampilkan informasi yang lebih akurat. 


\section{DAFTAR PUSTAKA}

[1] Heywood, I., Conelius, S., \& Carver. An Introduction to Geographical Information Systems. Prentice Hall. 2011.

[2] Hamdani, Dani., "Perancangan Sistem Informasi Pelaporan Online Kdrs Demam Berdarah Di Kota Bandung", Annual Research Seminar (ARS), 2017.

[3] The Unified Software Development Process: Classification of Iterations. Retrieved from http://www.idi.ntnu.no/emner/tdt4140/dokumenter/2009/unfied\%20process.ppt.

[4] Bentley, L. D., \& Whitten, J. L. Systems Analysis and Design for the Global Enterprise, 7th Edition, International Edition. New York: McGrawHill.2007. 